\title{
Knowledge and Utilization of Recommended Preventative Vaccines among Young Adults
}

Leena K Bhattacharya*, Melvin V Gerbie and Tina Q Tan

Leena K Bhattacharya, Hospitalist, Prentice Women's Hospital, Instructor in Pediatrics, Northwestern University Feinberg School of Medicine, Chicago, IL 60611, USA

\begin{abstract}
Background: Outbreaks of vaccine preventable diseases continue to be a problem, with recent epidemics of measles, pertussis and influenza causing notable morbidity and mortality. Recommended routine vaccination of the adult population has been low and sporadic.
\end{abstract}

Objectives: To examine the awareness, perception of risk, and knowledge of common vaccine preventable diseases in young adults. To assess utilization of vaccines (e.g. HPV, T dap and influenza), primary care provider recommendation of vaccines, and preventive healthcare trends in order to identify potential barriers to vaccination.

Methods: An anonymous, prospective survey of graduate students in Chicago.

Results: Survey was completed by 2,582 students; $53.3 \%$ were female. Seventy-eight percent were $18-26$ years of age; $23 \%$ of sexually active students did not use condoms. Ninety-five percent reported having health insurance, but $26 \%$ of males and $12 \%$ of females rarely or never sought routine medical care. Average knowledge scores were significantly higher for HPV than pertussis and influenza. Over $80 \%$ of students would be willing to ask their physician about vaccines. Fourteen percent of women and $9.4 \%$ of students had been vaccinated against HPV and pertussis respectively. Primary obstacles to vaccination were perception of not being at risk for disease, vaccine cost, and lack of time.

Conclusions: Despite media attention about various vaccine preventable diseases, a general awareness and openness towards vaccination, and adequate access to healthcare, the majority of young adults are not being offered or receiving recommended vaccinations. Personal risk perception and cost are major obstacles. New and creative interventions to reduce barriers to young adult vaccination are necessary.

Keywords: Vaccination; Pneumonia; Bacterial organisms; Influenza

\section{Introduction}

An estimated 50,000-90,000 Americans die of vaccine preventable diseases each year, the vast majority of these being adults. With the recent emergence of viral strains and bacterial organisms that have had more serious consequences in healthy young adults, routine vaccination of this population is a growing necessity. Furthermore, the healthcare cost of vaccine preventable diseases (VPDs) is substantial. For example, the yearly national economic burden of influenza disease is estimated to be $\$ 10.4$ billion in direct medical costs and a total economic burden of over $\$ 87$ billion [1]. If one takes into account the multiple other preventable diseases, the economic and health cost can be astronomical. The importance and urgency of this matter has become a major focus of both the Centers for Diseases Control and Prevention (CDC) and the Infectious Diseases Society of America. Increasing adult vaccination rates and awareness has become a public health priority. Because of the nature of transmissible diseases, immunization is important not only for an individual's health, but also for the health of the community at large.

Outbreaks of VPDs continue to be widely reported. Recently, measles outbreaks have routinely been featured in United States and world news [2]. In 2011 alone, there have been more than 37,000 cases of measles reported in the European region, with severe complications such as pneumonia and encephalitis occurring not infrequently $(1,482$ and 27 cases respectively). The largest number of cases occurred in France at over 15,000 [3]. Cases occurred predominantly among adolescents and young adults who had not been vaccinated. This resulted in a public health problem with spread of disease to other countries as infected persons have traveled abroad or unvaccinated persons traveled to Europe and contracted the disease. Low vaccine coverage and an unvaccinated population are the primary reasons for increased transmission and epidemics in the Western world [4]. Pertussis is a growing domestic and global problem, with increases in pertussis cases or recent outbreaks reported in a majority of the United States. There have been more than 41,000 cases and 18 deaths reported to the CDC in 2012. A substantial portion of the rise is attributable to increased rates of pertussis in adolescents and adults, who demonstrate waning vaccine-induced immunity over time. The majority of deaths, however, occur among infants younger than 3 months of age, primarily transmitted to them by their parents and caregivers $[5,6]$. According to the Advisory Committee on Immunization Practice (ACIP) and CDC, it is recommended that all adults should receive a single dose of Tdap and expectant mothers should receive Tdap during each pregnancy, regardless of the interval since prior Td/Tdap vaccination. In 2009, the emergence of a novel pandemic strain of influenza caused significant complications in healthy, young adults. Data from epidemiologic studies of the 2009-2010 influenza A (H1N1) pandemic indicate an increased risk of influenza complications among healthy adults in comparison to other influenza strains [7-9]. Since then, the US has adopted a strategy of universal vaccination. Despite this effort, the 2012-2013 influenza seasons have a laboratory-confirmed influenza-

*Corresponding author: Leena K Bhattacharya, Hospitalist, Prentice Women's Hospital, Instructor in Pediatrics, Northwestern University Feinberg School of Medicine, Chicago, IL 60611, USA, E-mail: Ibhattacharya@luriechildrens.org

Received March 18, 2013; Accepted March 28, 2013; Published March 30, 2013

Citation: Bhattacharya LK, Gerbie MV, Tan TQ (2013) Knowledge and Utilization of Recommended Preventative Vaccines among Young Adults. J Vaccines Vaccin 4: 179. doi:10.4172/2157-7560.1000179

Copyright: (c) 2013 Bhattacharya LK, et al. This is an open-access article distributed under the terms of the Creative Commons Attribution License, which permits unrestricted use, distribution, and reproduction in any medium, provided the original author and source are credited. 
Citation: Bhattacharya LK, Gerbie MV, Tan TQ (2013) Knowledge and Utilization of Recommended Preventative Vaccines among Young Adults. J Vaccines Vaccin 4: 179. doi:10.4172/2157-7560.1000179

Page 2 of 7

associated hospitalization rate of 36.7 per 100,000 populations, and the proportion of deaths attributed to pneumonia and influenza remains above the epidemic threshold, especially in the adult population [10].

Historically, adherence to guidelines for the administration of recommended routine vaccinations in the adult population has been low and sporadic $[11,12]$. Reasons for this are likely multi-factorial, involving barriers at the level of the patient and of the healthcare provider. These barriers include the widespread lack of awareness of disease and its associated morbidity, poor identification of personal risk factors, and misconceptions about the indication and value of vaccines, all of which contribute to low rates of vaccination. Based on data from multiple studies, it has been shown that individuals primarily look to their healthcare providers for information and recommendations about vaccines $[13,14]$. However, if the healthcare provider is unaware or not comfortable counseling about a vaccine, the patient is less likely to receive it. Young adults are a subset of the population who may have infrequent contact with physicians, as they are generally healthy and do not believe they need routine medical care. This results in inadequate vaccination of a key portion of the adult population. The lack of an organized and universal vaccine administration infrastructure for adults is also a major contributing factor to low immunization rates.

There are 12 vaccines that are currently licensed and recommended for use in the adult population as shown in (Figures 1a and 1b) $[15,16]$. This study surveyed an educated, young adult population to better understand the factors that contribute to immunization of this group. HPV, pertussis, and influenza are 3 vaccine preventable diseases that have particular relevance in the young adult population. All have been recently discussed in a wide variety of media venues and are examples of diseases for which vaccine is highly indicated in this population [17-25]

The objectives of this study were first to examine the awareness, health attitudes, perception of risk, and knowledge of common VPDs (e.g. HPV, pertussis, and influenza) in the young adult population. Secondly, we aimed to assess utilization of various recommended vaccines (e.g. HPV, Tdap and influenza), primary care provider (PCP) recommendation of the vaccines, and preventive healthcare trends in this group in order to identify potential barriers to vaccination.

\section{Methods}

A 54 item anonymous, prospective survey instrument was developed by the study team which addressed the knowledge, attitudes, barriers and utilization of three recommended adult vaccines (HPV, Tdap, and influenza) among a group of young professional adults (males and females). The survey was used to explore several topics, including: (1) student demographics, such as age, race, relationship status; (2) risk behaviors, including personal/sexual history, contraception, smoking; (3) healthcare utilization, frequency of PCP visits/routine screening, if offered and/or received vaccines; (4) knowledge about HPV, pertussis, and influenza infections and availability of vaccines; (5) attitude about vaccination and perceived risk. To obtain a knowledge score, 1 point was given for each disease knowledge question answered correctly, for a maximum score of 6,5 , and 4 for HPV, pertussis, and influenza respectively (Table 1 ). This study was reviewed and approved by the Institutional Review Board of the Children's Memorial Research Center prior to administration of the survey.

Recommended Adult Immunization Schedule-United States - 2013

Note: These recommendations must be read with the footnotes that follow

containing number of doses, intervals between doses, and other important information.

\begin{tabular}{|c|c|c|c|c|c|c|}
\hline VACCINE $\mathbf{v}$ AGE GROUP & $19-21$ years & $22-26$ years & $27-49$ years & $50-59$ years & $60-64$ years & 265 years \\
\hline Influenua ${ }^{2}$ & \multicolumn{6}{|c|}{1 dose annually } \\
\hline Ietanss, dphtheria, pertussis (Id//dap) 1" & \multicolumn{6}{|c|}{ Substitute 1-time dose of Tdap for Td booster; then boost with Td every 10 yrs } \\
\hline Varicellat $e^{*}$ & \multicolumn{6}{|c|}{2 doses } \\
\hline Human papillomavinus (HFV) Female 5* & \multicolumn{2}{|c|}{3 doses } & & & & \\
\hline Human papilonsavinus (HFV) Male 5* $^{*}$ & \multicolumn{2}{|c|}{3 doses } & & & & \\
\hline Zoster $^{6}$ & & & & & \multicolumn{2}{|c|}{1 dose } \\
\hline Measles, mumps, rubella (MMR) $)^{7 *}$ & \multicolumn{4}{|c|}{1 or 2 doses } & & \\
\hline Pneumococral poljsactharide (PPSVZZ) ${ }^{1 "}$ & \multicolumn{5}{|c|}{1 or 2 doses } & 1 dose \\
\hline Pneumococcal 13-valent corjogate (PCVI3) ${ }^{\text {") }}$ & \multicolumn{6}{|c|}{1 dose } \\
\hline Meningococcal ${ }^{\pi *}$ & \multicolumn{6}{|c|}{1 or more doses } \\
\hline Hepatitis $A^{Z^{*}}$ & \multicolumn{6}{|c|}{2 doses } \\
\hline Hepatitis B 13, & \multicolumn{6}{|c|}{3 doses } \\
\hline \multicolumn{7}{|l|}{ "Coverod by the Veccine Intery Compenotion Program } \\
\hline 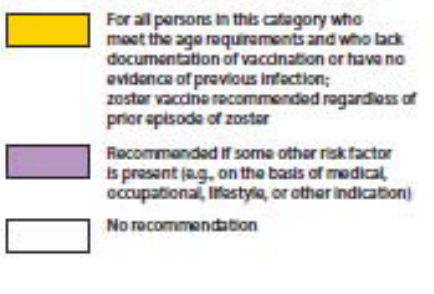 & \multicolumn{6}{|c|}{ 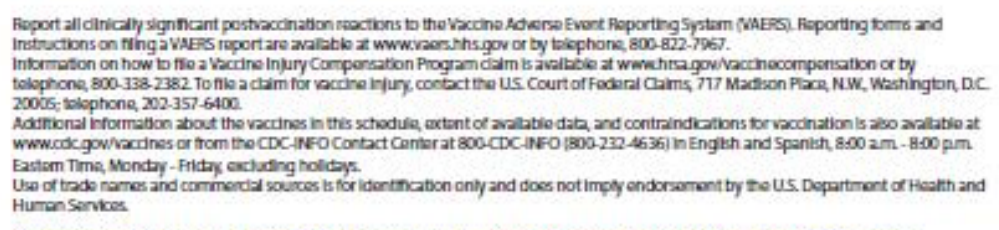 } \\
\hline
\end{tabular}

Figure 1a: Recommended Adult Immunization Schedule - United States, 2013 
Citation: Bhattacharya LK, Gerbie MV, Tan TQ (2013) Knowledge and Utilization of Recommended Preventative Vaccines among Young Adults. J Vaccines Vaccin 4: 179. doi:10.4172/2157-7560.1000179

Page 3 of 7

\section{HPV}

1 Is a vaccine available to prevent cervical cancer?

2 To which invasive cancer is HPV linked?

3 Which etiological agent causes genital warts?

4 Is having a history of abnormal PAP smear a reason not to receive HPV vaccine?

5 Would regular PAP smears be needed after HPV vaccination?

6 Would safe sex practices be needed after HPV vaccination?

\section{Pertussis}

1 Pertussis disease is associated with what type of symptoms?

2 The average duration of pertussis illness is?

3 Is immunity against pertussis, either via natural infection or vaccine, life long?

4 Is a pertussis vaccine for use in adults is licensed and available in the United States? Influenza

1 The most common complication of influenza is?

2 Routine influenza vaccination is recommended for which persons?

3 The best time to receive influenza vaccine is?

*all questions are multiple choices with options provided

Table 1: Knowledge score questions.

\begin{tabular}{|l|c|c|c|c|c|}
\hline \multicolumn{5}{|c|}{ Disease Knowledge Score } \\
\hline Disease/Vaccine & \multicolumn{2}{|c|}{$\begin{array}{c}\text { Medical } \\
\text { Students }\end{array}$} & \multicolumn{2}{|c|}{ Law Students } & $\begin{array}{c}\text { P values: } \\
\text { law vs. medical }\end{array}$ \\
\hline & Male & Female & Male & Female & \\
\hline HPV (max score = 6) & 4.53 & 5.03 & 3.34 & 4.85 & $<0.0001$ \\
\hline Pertussis (max score =4) & \multicolumn{2}{|c|}{1.66} & 0.82 & $<0.0001$ \\
\hline Influenza (max score = 3) & \multicolumn{2}{|c|}{1.73} & 1.40 & $<0.0001$ \\
\hline
\end{tabular}

Table 2: Mean disease knowledge scores.
The targeted study population consisted of medical students at six allopathic/osteopathic medical schools and law students at five law schools in Chicago, Illinois. This population serves as a "best-case scenario" for young adult vaccination given that they have above average level of education, good access to healthcare, and insurance coverage.

A pilot study was conducted and the survey was found to be a valid representation of students' knowledge and behavior. It was then administered to the participating institutions both by on campus (inperson) and online formats. In-person surveys were administered via the primary investigators or student liaison at each school and online surveys were sent via institutional email over the period from June 2007 to May 2008. Each participating student completed only one survey. The data was compiled and entered into a standardized data collection form.

Data analysis was conducted using SAS 9.1.3 (SAS Institute, Inc., Cary, NC). Statistical methods used included multivariate logistical regression, Cochran-Armitage test, student t-test, Fischer exact test, Chi-square analysis, and Wilcoxon rank sum test. $\mathrm{P}$ values $\leq 0.05$ were considered statistically significant. This study was funded by an unrestricted research grant from Sanofi Pasteur.

\section{Results}

Demographics and descriptive analyses of approximately 8,000 medical and law students enrolled at the eleven schools, 2,582 (32.28\%) students (1,764 medical and 818 laws) completed the survey; $53.3 \%$ were female. Seventy-eight percent were 18 to 26 years of age. Sixty-six percent were Caucasian, $20.6 \%$ were Asian, $4 \%$ were

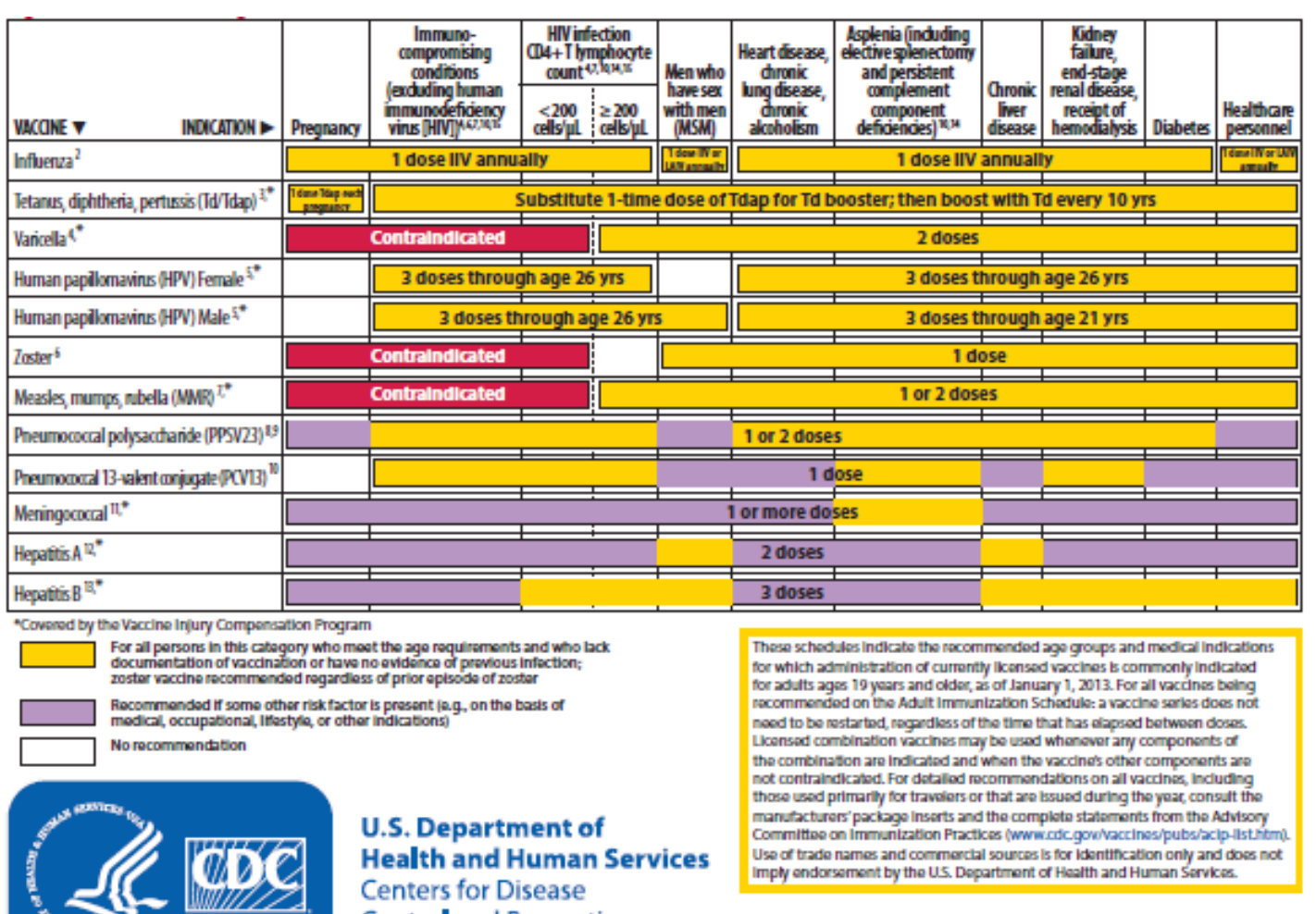

Centers for Disease

Control and Prevention

Centers for Disease Control and Prevention. Advisory Committee on Immunization Practices (ACIP) Recommended Immunization Schedule for Adults Aged 19 Years and Older - United States, 2013. MMWR / January 28, 2013 / Vol. 62.

Figure 1b: Vaccines that might be indicated for adults, based on medical and other indications - United States, 2013. 
Citation: Bhattacharya LK, Gerbie MV, Tan TQ (2013) Knowledge and Utilization of Recommended Preventative Vaccines among Young Adults. J Vaccines Vaccin 4: 179. doi:10.4172/2157-7560.1000179

Page 4 of 7

\begin{tabular}{|c|c|c|c|}
\hline & HPV vaccine & Tdap & Influenza vaccine \\
\hline $\begin{array}{l}\text { Female Gender vs. } \\
\text { Male Gender }\end{array}$ & $\begin{array}{c}p<0.0001 \\
\text { OR } 2.9(95 \% \mathrm{Cl}, 2.32 \text { to } 3.65)\end{array}$ & $\begin{array}{c}\mathrm{p}=0.0011 \\
\text { OR } 1.44(95 \% \mathrm{Cl}, 1.16 \text { to } 1.8)\end{array}$ & NS \\
\hline $\begin{array}{l}\text { Medical Student } \\
\text { vs. Law Student }\end{array}$ & $\begin{array}{c}\mathrm{p}=0.046 \\
\text { OR } 2.22 \text { (95\% Cl, } 1.89 \text { to } 2.7 \text { ) }\end{array}$ & $\begin{array}{c}\mathrm{p}=0.0002 \\
\text { OR } 1.93(95 \% \mathrm{Cl}, 1.68 \text { to } 2.27)\end{array}$ & $\begin{array}{c}\mathrm{p}<0.0001 \\
\text { OR } 1.69(95 \% \mathrm{Cl}, 1.51 \text { to } 1.94)\end{array}$ \\
\hline $\begin{array}{l}\text { Frequency of PCP } \\
\text { Visits }\end{array}$ & NS & $P=0.0004$ & $P=0.0012$ \\
\hline Sexually active & $\begin{array}{c}\mathrm{p}=0.0029 \\
\text { OR } 1.54(95 \% \mathrm{Cl}, 1.16 \text { to } 2.04)\end{array}$ & & \\
\hline $\begin{array}{l}\text { Greater number of } \\
\text { sexual partners }\end{array}$ & $p<0.0001$ & & \\
\hline
\end{tabular}

Table 3: Factors associated with willingness to ask physician about vaccine.

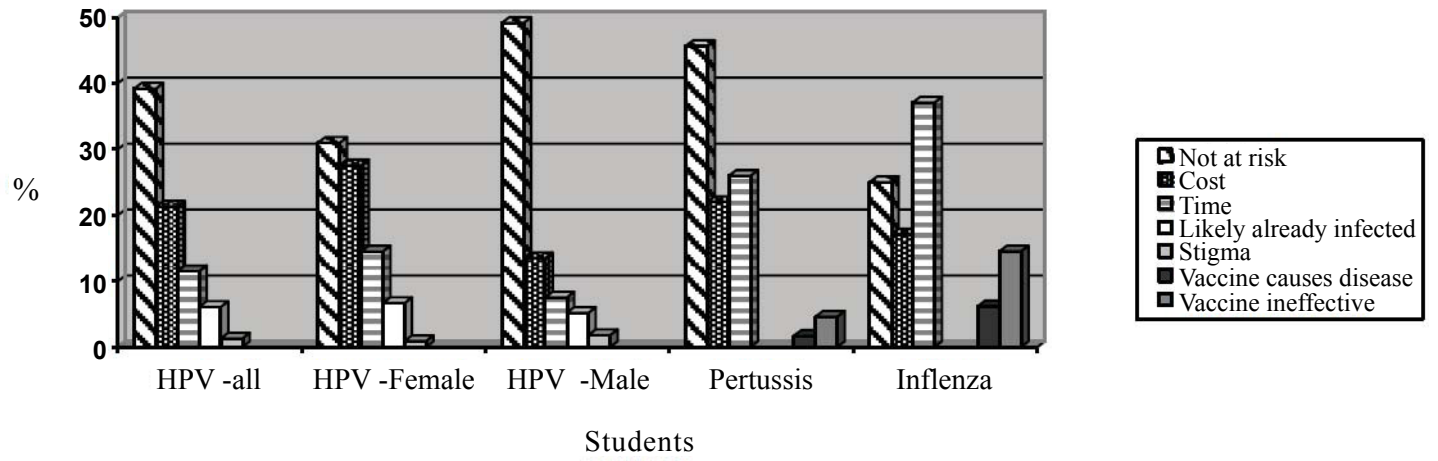

Figure 2: Perceived primary obstacles to vaccination.

African American, $4.5 \%$ were Hispanic, and 5\% were other races. The majority of the students (83.5\%) were either single or single but in a relationship; $15.7 \%$ were married and $4.5 \%$ had children. Almost $9 \%$ of students smoked, ranging from sometimes to daily. Of the sexually active students (86.3\%), 61\% became sexually active between 16 and 20 years of age with $43.3 \%$ having had 1 to 3 partners, $20.4 \%$ had 4 to 6 partners, $10.4 \%$ had 7 to 10 partners, and $11.8 \%$ more than 10 sexual partners. Law students reported significantly greater numbers of sexual partners than medical students. The vast majority (97\%) of the students were heterosexual, with 55\% using condoms regularly and 23\% rarely or never using condoms. Health care access and use Overall $95 \%$ of students reported having health insurance with the majority $(53.3 \%)$ covered by a student health plan and $30.3 \%$ covered by their parents' plan. However, almost $11 \%$ of the law students reported not having health insurance. Family practice (FP) (37\%) and internal medicine (IM) (21.2\%) physicians were the most common specialties used as primary care physicians. Twenty-eight percent of students used student health service physicians, and $25 \%$ of females identified obstetriciangynecologists $(\mathrm{Ob} / \mathrm{Gyn})$ as their primary health care source. Thirty percent of males and $45.4 \%$ of females saw their PCP on a yearly basis, while $26 \%$ of males and $12 \%$ of females rarely or never sought routine medical care. Males were significantly less likely to obtain routine preventative health care compared to females, $\mathrm{p}<0.0001$. The majority of the sexually active female students (74.5\%) received annual pelvic exams and Papanicolaou (Pap) smears. Five percent of the sexually active and $48.6 \%$ of non- sexually active women had never had a pelvic exam or Pap smear. In our cohort, $13.3 \%$ of the women tested positive in the past for HPV and $21.5 \%$ reported a history of an abnormal Pap smear.

\section{Knowledge}

Not surprisingly, medical students had higher knowledge scores than law students for all three VPDs. Overall $98.5 \%$ of students correctly identified HPV as the cause of cervical cancer [26]; only $65 \%$ identified HPV as the cause of genital warts. Twenty-five percent of students thought that herpes was the cause of genital warts. Eightythree point seven percent of students were aware of an available HPV vaccine; female students more aware than male students, $88.9 \%$ vs. $77.7 \%, \mathrm{p}=<0.0001$, and medical students more aware than law students, $89.5 \%$ vs. $71.1 \%, p=<0.0001$. Sixty-five point five percent of the students identified persistent cough as the symptom associated with pertussis disease; $77.7 \%$ of medical students vs. $34.5 \%$ of law students $\mathrm{p}=<0.0001$. Seventy-two point seven percent of the students knew that there was a pertussis vaccine available for adults. Forty-four percent of the students identified pneumonia as the most common complication of influenza. Knowledge scores for these infections are shown in (Table 2).

\section{Vaccination}

Eighty-three to $86.6 \%$ of students would be willing to ask their physician about HPV, pertussis, or influenza vaccines. Seventy to $76 \%$ of students would consider receiving HPV and/or pertussis vaccines. By logistic regression analysis, factors that increased willingness to ask their physician about vaccination included: female gender, medical school student, higher number of lifetime sexual partners, and frequency of visit to their PCP (Table 3). Overall, students would ask PCPs in all specialties about each vaccine, although most women preferred to ask their Ob/Gyn specifically about HPV vaccine.

Female students reported that $31.8 \%$ of their PCPs had recommended the HPV vaccine, with only $14.4 \%$ having received one or more doses of vaccine. Ob/Gyn had recommended the HPV vaccine to $54.2 \%$ of the vaccinated women. Thirteen percent of students reported that their PCP had recommended pertussis vaccine. Only 9.4\% of students had been vaccinated against pertussis. Fifty-eight percent reported receiving influenza vaccine at some time in the past, and $48 \%$ had a physician recommend influenza vaccine to them. FP and 
IM physicians were most likely to recommend pertussis and influenza vaccination.

Primary obstacles to receiving vaccinations were perception of not being at risk for disease (25 to $45.7 \%$ ), vaccine cost (17.2 to $22 \%$ ), and lack of time (11.5 to $37.1 \%)$. Male students were more likely than female students to consider themselves not at risk for HPV infection $49.2 \%$ vs. $31.3 \% p=<0.0001$. Belief that vaccine is ineffective was a barrier for influenza (14.5\%) and pertussis $(4.6 \%)$ vaccines. Although $6 \%$ of students felt that influenza vaccine caused influenza and $1.7 \%$ thought Tdap vaccine caused pertussis, these numbers are relatively low (Figure 2).

\section{Discussion}

This study is one of the first large surveys of young adults to examine knowledge and perceived risk of various vaccine preventable diseases (e.g. HPV, pertussis, and influenza) and utilization of preventive vaccines. Our results specifically show that this population has good basic knowledge of certain VPDs such as HPV and its most serious complications, but less knowledge about influenza and pertussis. Significant gaps exist in perception of personal disease risk and misconceptions about vaccine adverse effects, which in turn affect vaccine utilization.

Media publicity, in the case of HPV and yearly influenza epidemics, seems to contribute significantly to young adults' disease awareness. However, advertisements alone do not significantly influence vaccine uptake [27]. Similarly, public service announcements for pertussis vaccination targeting new/expectant mothers and close contacts for protection of their young infants has not resulted in a significant increase in vaccination rates. These efforts with a message directed specifically at young adults need to be increased to help educate these individuals regarding the consequences of VPDs and importance of routine adult vaccinations.

Despite media attention about outbreaks of various vaccine preventable diseases, a general awareness and openness towards vaccination, and adequate access to healthcare, our results show that the vast majority of young adults are still not seeking out, being offered, or receiving appropriate vaccinations. Media advertisements increase awareness, but do not necessarily result in accurate knowledge about VPD risk and the vaccination [27]. Although the majority of students were aware of influenza vaccine, yearly utilization is still inadequate [28]. Young adults with less knowledge of VPDs and disease prevention tend to have higher rates of risk behaviors and lower rates of vaccination. Our study shows that perception of personal risk of VPDs is particularly lacking and remains an educational challenge. Knowledge of disease consequence does not necessarily translate into accurate perception of one's personal risk and is likely one of the main factors responsible for low uptake of vaccines. For this reason, providers play a particularly integral role in vaccine education for each individual patient.

Since physicians and student health departments are the resources young adults look to for information and discussion on vaccination, it is necessary for all PCPs to understand the importance of vaccination and be routinely counseling about vaccines as recommended by the CDC and professional specialty organization practice guidelines [12,19,2931]. Education focused on both personal consequences of disease and communicability of illnesses to vulnerable close contacts is necessary. Open conversation about risk behaviors, the prevalence of VPDs in society, and strong recommendation for vaccination will likely is useful. According to the CDC NIS vaccination coverage surveys reports, $78.2 \%$ of adolescents but only $8.2 \%$ of adults have received Tdap vaccine [3234]. Immunization of the adult population should become an active part of routine adult primary care physicians' office practice, as is the case in for children and adolescents. Studies of adult PCPs demonstrate that poor reimbursement and lack of knowledge and training in vaccine use are major factors that prevent providers from offering vaccines $[35,36]$. Providers need to be familiar and comfortable with discussion of vaccination, answering patient's questions, and ideally be both financially and logistically equipped to administer vaccines. Part of the Affordable Care Act (ACA), passed in March of 2012, is the Prevention and Public Health Fund with a renewed focus on prevention, including improvement in the delivery of vaccinations to adults. It offers a series of recommendations aimed at integrating the delivery of advice about vaccination into routine office-based care and the development of tools and incentives to encourage providers who do not offer vaccination to refer adult patients to community vaccinators. The program supports the development and use of non-traditional venues such as pharmacies, retail-based clinics, and nurse practitioners as alternatives to the physician's office to vaccinate patients $[37,38]$. There is a need for continuing educational programs for physicians on the indications and effects of vaccines and resources for vaccination. Because healthcare provider recommendation is a key factor determining whether an adult patient will be vaccinated, it is imperative that providers are themselves educated and can counsel their patients in depth on the benefits of vaccination against VPDs and the safety of vaccines [39].

Perceived vaccine cost, was reported as a major barrier to utilization of recommended vaccines. Historically, adult immunizations were very poorly reimbursed by insurance companies, and at the time of this study, most student health insurance policies did not cover vaccination [40]. A survey of all US and Canadian medical schools in 2007, for example, showed that over half of student health policies provided no coverage for HPV vaccination [41]. Reimbursement structures for adult vaccines such as HPV and Tdap have improved considerably since then. The ACA's Section 317 Immunization Program provides grants to all states to provide vaccines for uninsured and underinsured citizens, including adults, who are not covered by another federal initiative. It is unclear whether the change has been perceived by young adults and more importantly by their healthcare providers. Physician practices should be willing to have means of providing vaccines in the office, which requires financial investment and planning, or be equipped to refer their patients to alterative centers to receive vaccine. Cost issues and coverage of vaccines for young adults need to be addressed and clarified to healthcare consumers and their physicians.

\section{Limitations}

The data collected were through a self-reported questionnaire. Inaccurate reporting of personal information is possible, although efforts were made to minimize this risk by guaranteeing anonymity. As previously noted, the study participants were recruited from a general graduate (medical and law) student population. Similar questions addressed to a more general population might provide different data and remove the bias of having potential background medical knowledge/ experience. Since PCPs (IM, FP, Ob/Gyn) play a role in providing much of the primary care and vaccines for this population, additional research is needed to better understand gaps in knowledge and obstacles to adult vaccination from the healthcare provider's perspective, such as the financial burden of vaccination on a physician's practice. This would guide the educational efforts that need to be developed to address these issues. 
Citation: Bhattacharya LK, Gerbie MV, Tan TQ (2013) Knowledge and Utilization of Recommended Preventative Vaccines among Young Adults. J Vaccines Vaccin 4: 179. doi:10.4172/2157-7560.1000179

\section{Conclusion}

Widespread adult vaccination against VPDs has the potential to prevent significant morbidity and mortality in adults and in the population at large. Our study demonstrates that despite good baseline awareness of certain VPDs, the utilization of vaccines, personal risk perception, and understanding of the benefits of vaccination are poor in this population. Primary care and student health physicians need to become better educated on the recommendations for the use of vaccines. They also need to counsel their patients and provide access. Adult vaccination must become a part of routine preventative care. Targeted media coverage with specific messages aimed at this population may help reach this objective. Cost issues for young adults with and without health insurance and non-traditional venues for vaccination need to be clarified. It is clear that new and creative approaches to reducing barriers to vaccination against VPDs are necessary in order to increase vaccination rates in young adults.

\section{Acknowledgements}

We would like to acknowledge the following persons for their contribution and support of this study: Elizabeth King for development of online survey form, Anika Dutta for data entry, and the student liaisons and deans at participating schools: Taylor Heald, Seema Masterson, Anish Parikh, William Powers, MadihaRaina, Prashanthi Rao Raman, Alex Tanz, Anupama Topgi, Katherine Tarlock, Antonia Scholz, Stephen Sowle, Shikha Wadhwani, and Tiffany Wang.

\section{References}

1. Molinari NA, Ortega-Sanchez IR, Messonnier ML, Thompson WW, Wortley PM, et al. (2007) The annual impact of seasonal influenza in the US: measuring disease burden and costs. Vaccine 25: 5086-5096.

2. (2011) Measles: United States, January-May 20, 2011. MMWR 60: 666-668.

3. Measles Surveillance Data: Reported Measles Cases by WHO region 2011, 2012 as of 05 February 2013. World Health Organization.

4. (2011) Weekly Epidemiological Record. 86: 557-564.

5. Pertussis Outbreaks (2013) National Center for Immunization and Respiratory Diseases, Division of Bacterial Diseases. Centers for Disease Control and Prevention.

6. Paisley RD, Blaylock J, Hartzell JD (2012) Whooping Cough in Adults: An Update on a Reemerging Infection. Am J Med 125: 141-143.

7. Jain S, Kamimoto L, Bramley AM, Schmitz AM, Benoit SR, et al. (2009) Hospitalized patients with 2009 H1N1 influenza in the United States, April-June 2009. N Engl J Med 361: 1935-1944.

8. Louie JK, Acosta M, Winter K, Jean C, Gavali S, et al. (2009) Factors associated with death or hospitalization due to pandemic 2009 influenza A (H1N1) infection in California. JAMA 302: 1896-1902.

9. Girard MP, Tam JS, Assossou OM, Kienv MP (2010) The 2009 A (H1N1) influenza virus pandemic: A review. Vaccine 28: 4895-4902.

10. Fluview: A weekly influenza surveillance report prepared by the influenza division. Centers for Disease Control and Prevention.

11. Euler GL, Lu P, Singleton JA (2008) Vaccination coverage among US adults, National Immunization Survey 2007. Centers for Disease Control and Prevention for Immunization and Respiratory Diseases.

12. Shefer A, Briss P, Rodewald L, Bernier R, Strikas R, et al. (1999) Improving immunization coverage rates: an evidence-based review of the literature. Epidemiol Rev 21: 96-142.

13. Johnson DR, Nichol KL, Lipczynski K (2008) Barriers to adult immunization. Am J Med 121: S28-35.

14. Briss PA, Rodewald LR, Hinman AR, Shefer AM, Strikas RA, et al. (2000) Reviews of evidence regarding interventions to improve vaccination coverage in children, adolescents, and adults. The Task Force on Community Preventive Services. Am J Prev Med 18: 97-140.

15. Fedson DS (1994) Adult immunization: summary of the national vaccine advisory committee report. JAMA 272: 1133-1137.
16. Bridges CB, Woods, L, Coyne-Beasley T (2013) Centers for Disease Contro and Prevention. Recommended adult immunization schedule - United States 2013. Ann Intern Med 158: 191-199.

17. Revzina NV, Diclemente RJ (2005) Prevalence and incidence of human papillomavirus infection in women in the USA: a systematic review. Int J STD AIDS 16: 528-537.

18. Weinstock H, Berman S, Catee W (2004) Sexually transmitted diseases among American youth: incidence and prevalence estimates, 2000. Perspect Sex Reprod Health 36: 6-10.

19. Burk RD, Ho GYF, Beardsley L, Lempa M, Peters M, et al. (1996) Sexua behavior and partner characteristics are the predominant risk factors for genital human papillomavirus infection in young women. J Infect Dis 174: 679-689.

20. Ho GYF, Bierman R, Beardsley L, Chang CJ, Burk RD (1988) Natural history of cervicovaginal papillomavirus infection in young women. N Engl J Med 338 423-428.

21. Vetter KM, Geller SE (2007) Moving forward: human papillomavirus vaccination and the prevention of cervical cancer. J Womens Health (Larchmt) 16:12581268.

22. Brooks DA, Clover R (2006) Pertussis infection in the United States: role for vaccination of adolescents and adults. J Am Board Fam Med 19: 603-611.

23. Kretsinger K, Broder KR, Cortese MM, Kretsinger K, Slade BA, et al. (2006) Preventing tetanus, diphtheria, and pertussis among adolescents: use of tetanus toxoid, reduced diphtheria toxoid and acellular pertussis vaccines recommendations of the Advisory Committee on Immunization Practices (ACIP). MMWR Recomm Rep 55: 1-34.

24. De Serres G, Shadmani R, Duval B, Boulianne N, Déry P, et al. (2000) Morbidity of Pertussis in Adolescents and Adults. J Infect Dis 182: 174-179.

25. Lee GM, Lett S, Schauer S, LeBaron C, Murphy TV, et al. (2004) Societal Costs and Morbidity of Pertussis in Adolescents and Adults. Clin Infect Dis 39: 1572 1580.

26. Walboomers JM, Jacobs MV, Manos MM, Bosch FX, Kummer JA (1999) Human papillomavirus is a necessary cause of invasive cervical cancer worldwide. J Pathol 189: 12-19.

27. Almeida CM, Tiro JA, Rodriguez MA, DiamantAL (2012) Evaluating associations between sources of information, knowledge of the human papillomavirus, and human papillomavirus vaccine uptake for adult women in California. Vaccine 30: 3003-3008.

28. (2009) Influenza vaccination coverage among children and adults - United States, 2008-2009 influenza season. Centers for Disease Control and Prevention (CDC). MMWR 58: 1091-1095.

29. Markowitz LE, Dunne EF, Saraiya M, Lawson HW, Chesson H, et al. (2007) Quadrivalent Human Papillomavirus Vaccine: Recommendations of the Advisory Committee on Immunization Practices (ACIP). MMWR 56: 1-24.

30. (2010) FDA licensure of quadrivalent human papillomavirus vaccine (HPV4 Gardasil) for use in males and guidance from the Advisory Committee on Immunization Practices (ACIP). Centers for Disease Control and Prevention (CDC). MMWR 59: 630-632.

31. Prevention and Control of Influenza with Vaccines (2012) Recommendations of the Advisory Committee on Immunization Practices (ACIP) United States, 2012-13 Influenza Season. MMWR 61: 613-618

32. Centers for Disease Control and Prevention (2011) National and State Vaccination Coverage among Adolescents Aged 13-17 Years: United States, 2011. MMWR 61: 671-677.

33. Schiller JS, Euler GL (2008) National Center for Health Statistics, Centers for Disease Control and Prevention. Vaccination coverage estimates from the National Health Interview Survey: United States, 2008.

34. Centers for Disease Control and Prevention (2012) Adult Vaccination Coverage: United States, 2010. MMWR 61: 66-72.

35. Tan TQ, Bhattacharya L, Gerbie MV (2011) Awareness, perceptions and knowledge of recommended adult vaccines among a nationwide sample of adult primary care providers. J Reprod Med 56: 301-307.

36. Stovall DW, Loveless MB, Walden NA, Karjane N, Cohen SA (2007) Primary and preventive healthcare in obstetrics and gynecology: a study of practice patterns in the mid-atlantic region. J Womens Health (Larchmt) 16: 134-138. 
Citation: Bhattacharya LK, Gerbie MV, Tan TQ (2013) Knowledge and Utilization of Recommended Preventative Vaccines among Young Adults. J Vaccines Vaccin 4: 179. doi:10.4172/2157-7560.1000179

Page 7 of 7

37. Forsberg V, Fichtenberg C (2012) The Prevention and Public Health Fund: A critical investment in our nation's physical and fiscal health. American Public Health Association Center for Public Health Policy.

38. Harris KM, Uscher-Pines L, Mattke S, Kellermann AL (2012) A Blueprint for Improving the Promotion and Delivery of Adult Vaccination in the United States. RAND Corporation.

39. Adult immunization: knowledge, attitudes and practices - DeKalb and Fulton Counties, Georgia, 1998. MMWR 37: 657-61.
40. Mclntyre-Seltman K, Castle PE, Guido R, Schiffman M, Wheeler CM (2005) Smoking is a risk factor for cervical intraepithelial neoplasia grade 3 among oncogenic human papillomavirus DNA-positive women with equivocal or mildly abnormal cytology. Cancer Epidemiol Biomarkers Prev 14: 11651170.

41. Gee RE, Hannah Shacter E, Judith Long A (2009) Coverage of human papillomavirus vaccine by US and Canadian medical schools. Journal of Lower Genital Tract Disease 13: 207-209. 